\title{
Coal and Biomass Co-Pyrolysis in a Fluidized-Bed Reactor: Numerical Assessment of Fuel Type and Blending Conditions
}

\author{
Tamer M. Ismail ${ }^{1 *}$, S.W.Banks ${ }^{2}$, Y. Yang ${ }^{2}$, Haiping Yang ${ }^{3 *}$, Yingquan Chen ${ }^{3}$, \\ A.V. Bridgwater ${ }^{2}$, Khaled Ramzy ${ }^{1}$ and M. Abd El-Salam ${ }^{4}$
}

\author{
${ }^{1}$ Mechanical Engineering Department, Suez Canal University, Ismailia, Egypt; \\ ${ }^{2}$ Enery and Bioproducts Research Institute, Aston University, Birmingham B4 7ET, United Kingdom; \\ ${ }^{3}$ State Key Laboratory of Coal Combustion, Huazhong University of Science and Technology, 1037 \\ Luoyu Road, 430074, Wuhan, P. R. China; \\ ${ }^{4}$ Department of Basic Science, Cairo University, Giza, Egypt.
}

\section{ABSTRACT}

Co-pyrolysis is one of the most promising options for using coal and biomass because coal is low in hydrogen and biomass can supplement the hydrogen content to make a more valuable and reactive product gas. The mixture of coal and biomass is prepared, with the mass ratio of biomass varying between 0 and $100 \%$. Due to limitations in experimental methods, the data points measured in these studies are coarse and therefore, insufficient for kinetic energy analysis and model comparison. Therefore, a mathematical model has been proposed to combine a study of the influence of experimental parameters with different materials to understand better the effect of these parameters on pyrolysis with the rigorous control of experimental conditions in terms of precision and repeatability. The advantages of mathematical modelling co-pyrolysis make it possible to design a reaction scheme capable of describing this phenomenon and extracting kinetic parameters, making it possible to compare fuels, which can be used for the simulation of this process in thermal power plants. The experimental analysis of measured co-pyrolysis data was taken from literature work to validate the proposed model. The numerical model results are in good agreement with the experimental data for co-pyrolysis. The most significant degree of synergetic effects on the product yields was observed at $600{ }^{\circ} \mathrm{C}$ and a biomass blending ratio of $70 \mathrm{wt} . \%$. Furthermore, the improvement of char reactivity also identifies the synergies in copyrolysis.

Keywords: co-pyrolysis, coal, biomass, mathematical model.

\section{Introduction}

A solid fuel exposed to a sufficient quantity of heat, under an oxidizing or inert gas atmosphere, can undergo several thermochemical transformations. Total conversion takes place under an oxidizing atmosphere. The solid part of the fuel is reduced to the incombustible residue (ash) after the volatiles have left, and the solid residue has burned. Fig. 1 illustrates the corresponding stages: dehydration, pyrolysis, oxidation of volatile matter and degradation combustion of the solid carbonaceous residue [1]. This residue, resulting from devolatilization, is consumed by a heterogeneous oxidation mechanism in the presence of oxygen (combustion process) or the presence of $\mathrm{CO}_{2}$ and water vapor (gasification process) or by both simultaneously. 


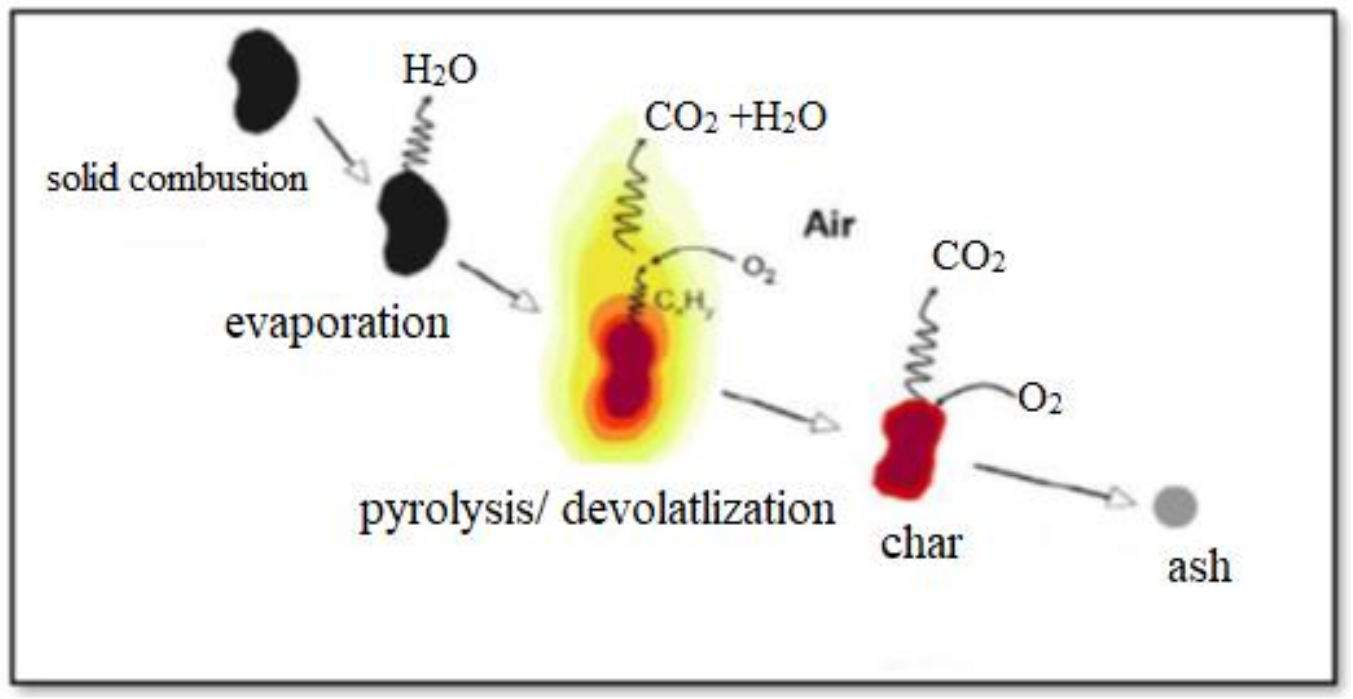

Fig.1 Thermal conversion of solid fuel [1]

The pyrolysis or devolatilization step is considered the initial step of thermal conversion of solid fuels. It has a strong influence on processes such as combustion and gasification [2, 3]. This conversion step controls fuel ignition, flame stability, particle swelling, soot formation. The pyrolysis process is detailed in more detail below.

Pyrolysis is a very complex transformation that involves many reactions. It takes place under the action of heat and in the absence of oxygen. This process includes heat and mass transfer phenomena allowing the release of a set of organic and inorganic gaseous compounds, as well as condensable compounds, from the particle surrounded by the inert atmosphere. The release of these products is mainly caused by the temperature increase within the particle (thermal cracking reactions). Three main fractions are produced during pyrolysis: a solid residue (char), non-condensable light gases $\left(\mathrm{H}_{2}, \mathrm{CO}\right.$, $\mathrm{CO}_{2}, \mathrm{H}_{2} \mathrm{O}$ and $\mathrm{CH}_{4}$ ) and a condensable fraction (oils and tars). Tars are composed of several relatively heavy organic rings and inorganic molecules. They escape the solid matrix of fuel in both gas and liquid form [4].

Fig. 2 gives a simplified diagram describing the steps of pyrolysis of a biomass particle. The heat transfer between the particle and reaction medium is initially carried out by convection and radiation. Then conductive heat transfer takes place within the particle. According to this model, two pyrolysis mechanisms are distinguished. Primary pyrolysis leads to the formation of three fractions, char, non-condensable gases and condensable vapours [5]. Secondary pyrolysis involves homogeneous and heterogeneous reactions of the primary pyrolysis products, such as cracking tars and heterogeneous reactions between the carbonaceous residue and gases. In the rest of this work, the term "pyrolysis" encompasses both phases. 


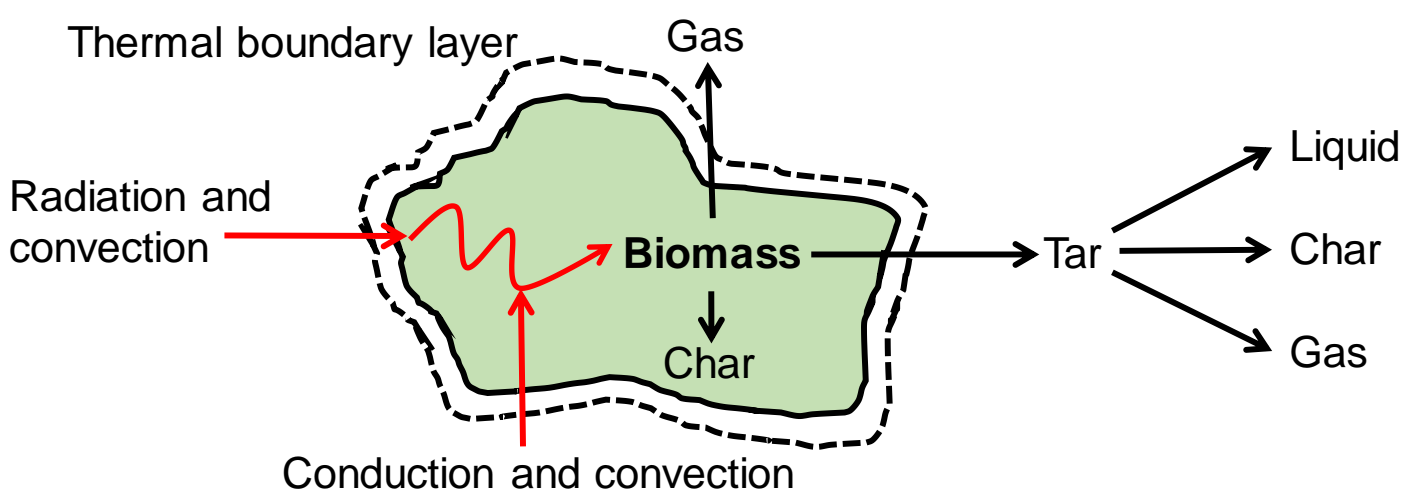

Fig. 2 Pyrolysis of a biomass particle

Experimental pyrolysis studies can be grouped into three types (slow, intermediate and fast). The difference lies mainly in the rate of heating of the combustible particles. According to Souza-Santos [4], pyrolysis is said to be "slow" when the heating rate is less than $10 \mathrm{~K} \mathrm{~s}^{-1}$. It is considered "fast" when the heating rate is greater than $103 \mathrm{~K} / \mathrm{s}$.

Several parameters have a direct or indirect influence on the yield, composition and characteristics of the chemical species released during devolatilization. These are intrinsic parameters related to the nature, composition and structure of the fuel, and external parameters such as temperature, heating rate, pyrolysis atmosphere and pressure.

Coal is considered one of the most significant fossil fuel energy sources in the world. The reserves were was expected to be 200 years compared with the natural gas and crude oil whose their reserve was expected to be 65 years and 40 years respectively. Coal pyrolysis can produce liquids, and different chemicals; however, yields are limited due to the low hydrogen content of coal. Hydropyrolysis is an interesting method to improve liquid quality and yield, but the high hydrogen cost hinders its application in the industry [5]. If hydrogen is needed for coal processing, there are several potential sources such as polymers, coke-oven gas, petroleum residues and plastic wastes. Biomass is considered a more prospective source to replace fossil fuels in the future compared with plastic wastes. This is because biomass is renewable, abundant, carbon dioxide neutral and clean. Both coal and biomass are carriers of accumulated solar energy. The composition difference from biomass to coal is mainly due to oxygen contents and can be explained using a Van Krevelen diagram in terms of oxygen/carbon $(\mathrm{O} / \mathrm{H})$ and hydrogen/carbon $(\mathrm{H} / \mathrm{C})$ ratios [5].

It can be seen that biomass has a higher $\mathrm{H} / \mathrm{C}$ ratio $(1.26-1.58)$ and $\mathrm{O} / \mathrm{C}$ ratio $(0.4-0.8)$ compared to coal. The high hydrogen contents of biomass suggest that biomass could act as a hydrogen donor in co-pyrolysis with coal. Also, pyrolysis is inherent to be carried out in an inert atmosphere, whereas the higher oxygen content in biomass provides a significant increase in the reactivity of the pyrolysis environment, thereby contributing to the conversion of coal [6]. 
Research on co-pyrolysis is a debatable field. Its primary focus is on improving the thermal transformation of coal. Many researchers have studied co-pyrolysis of coal and biomass blends. Most previous studies [7- 12] support the lack of synergistic effect between coal and biomass.

More recent efforts [13 - 18] show the significant interactions of the co-pyrolysis in TGA. Other researchers [19 - 25] have verified the synergy effect on the yields of the significant pyrolytic products, gaseous component, tar components, and the reactivities of the chars. The results showed some beneficial synergies between the biomass and coal.

According to the literature review on co-pyrolysis of biomass and coal, no studies regarding the numerical modeling of co-pyrolysis systems. The main objective of the present study is to discuss the synergetic effects of co-pyrolysis of biomass and coal, a numerical model is presented based on the experimental studies.

So the objectives of this work were to develop a new mathematical model. For the coal pyrolysis, the Kobayashi model [26] will be used. The kinetic scheme considers that the fuel devolatilises in two stages respectively at high and at low temperatures. Simple phenomenological models, such as that proposed by Kobayashi model, consider competitive and/or independent reactions to describe the products formed. However, the exact nature of these products remains unclear. The reactions proposed by these models contain several kinetic parameters which are determined by comparison with the experimental data.

One of the advantages of the present model is that the competing reactions reduce to a single reaction when the second reaction is much slower than the first one. Therefore kinetic parameters obtained under relatively low temperatures assuming a single overall reaction can be utilized for the first reaction [27].

For the case of biomass, two models are proposed: the Single Reaction Model (SRM) to simulate fast pyrolysis and the Independent Parallel Reaction (IPR) model to simulate lignocellulose structure by each of its components: cellulose, hemicellulose and lignin. The presented model also looked for a reaction scheme that allows simulating the devolatilisation of biomass over a wide range of heating rates.

Therefore a developed model for the co-pyrolysis was proposed to combine a study of the influence of experimental parameters (conversion atmosphere, temperature, residence time, etc.) with different materials (coals and biomass) for better understand the effect of these parameters on pyrolysis with the most rigorous control of experimental conditions in terms of precision and repeatability.

This allows for both coal and biomass pyrolysis mechanisms under different conditions to be modelled. Pyrolysis is a critical step in determining sample ignition, flame stability, fluidity, particle swelling, and emissions of gaseous and particulate pollutants. Better devolatilization of coal leads to more efficient combustion. Devolatilisation is a complicated step in the process of thermal degradation and is highlighted in this study. 


\section{Mathematical Model}

The method of coupling a numerical model with particle energy equations is used to model the pyrolysis process. The model predicts particle pyrolysis with different particle diameters, fuel types and blending ratios. The pyrolysis of mixed biomass and coal particles are modelled by simply adding the characteristics of biomass and coal pyrolysis separately, which also means that there is no interaction between coal and biomass quality or quantity.

Kinetic modelling of pyrolysis allows for the design of a reaction scheme capable of describing this phenomenon and extracting kinetic parameters. This makes it possible to compare fuels and can be used, for example, in thermal power stations. The identification of actual reaction schemes is extremely complex due to the existence of the many reactions and products involved. The complexity of the reactions and products is the reason why most of the kinetic models proposed in the literature are based on simplified schemes. As mentioned earlier, these simplified models are useful for simulation software for optimizing the operation of industrial boilers using solid fuels $[28,29]$.

\section{Coal Pyrolysis}

The main models for determination of devolatilization kinetics and distribution of pyrolysis products are given below.

The present model represents coal as a number of functional groups that are decomposed by parallel and independent reactions. This model has become the basis of several more detailed and sophisticated models [30].

The FG-DVC structural model integrates the functional group model (FG) for gas evolution and a second statistical model for tar formation. The tar formation model introduces depolymerization, cross-linking (DVC), and internal and external transport reactions [31].

The FG-DVC model combines two sub-models to predict the behavior of primary pyrolysis:

- the FG model describes the evolution of gases and the changes in the composition of functional groups in tanks and tars

- the DVC model describes the yields, molecular mass and specific properties of condensable vapors and char.

In order to improve the model and make it applicable in the case of secondary pyrolysis reactions, Serio et al. [32] have integrated two additional sub-models of secondary reactions:

- the hydrocarbon cracking model which describes the cracking of paraffins and olefins to form light gaseous species.

- the equilibrium model which describes the behavior of gaseous species containing oxygen, hydrogen and carbon at high temperature.

The FG sub-model is the most widely used to predict the devolatilization of coal. Its main features are: 
- All coals can be characterized by a set of functional groups and differ in the concentration of these different groups. Nineteen functional groups were chosen by Solomon [33] and Serio et al. [32] to represent the structures of coals.

- The number of functional groups corresponding to each gas species is determined by thermogravimetry coupled to an Infrared Fourier Transform Spectrometer.

Coal reactions are represented by a set of functional groups that are supposed to not interact with each other. The FG model has been validated under different operating conditions and makes it possible to correctly predict the distribution of primary coal pyrolysis products [33].

The dimensions of the fuel changed and the diameter of the spherical particle varied. Thus, the effects of swelling, shrinkage or breakage are taken into account.

This kinetic scheme proposes the hypothesis that the pyrolysis of coal can be represented by two competitive reactions, simplifying the complex phenomenon of pyrolysis, which includes several reactions [34].

In this model, coal is represented by $\mathrm{CH}_{x}$. The two competitive reactions of pyrolysis are:

$\mathrm{CH}_{x} \rightarrow \alpha_{1} \mathrm{CH}_{x 1}+\left(1-\alpha_{1}\right) C_{\text {residual } 1}$

$\mathrm{CH}_{x} \rightarrow \alpha_{2} \mathrm{CH}_{x 2}+\left(1-\alpha_{2}\right) C_{\text {residual } 2}$

$\mathrm{CH}_{x 1}$ shows the light volatiles produced by reaction $\mathrm{R} 1, \mathrm{CH}_{x 2}$ shows the heavy volatiles produced by reaction R2. $C_{\text {residual } 1}$ and $C_{\text {residual } 2}$ represent the carbon residues resulting from the two reactions. $\alpha_{1}$ and $\alpha_{2}$ are stoichiometric coefficients used to check the material balance ( $\alpha_{1}$ and $\alpha_{2}$ are less than 1). The reaction (R1) predominates at low temperature $\left(\mathrm{T}<1100^{\circ} \mathrm{C}\right)$. The reaction $(\mathrm{R} 2)$ predominates at high temperature (T>1100 $\left.{ }^{\circ} \mathrm{C}\right)$. The latter produces heavier volatiles: the coefficient $\alpha_{2}$ is greater than $\alpha_{1}$. It is generally 1.1 to 1.8 times greater than $\alpha 1$ [35].

Model equations for

- Devolatilization

The devolatilization speeds, for both reactions, are:

$V_{1}\left(k g s^{-1}\right)=\alpha_{1} m_{\text {coal }}(t) k_{1}(t)$

$V_{2}\left(k g s^{-1}\right)=\alpha_{2} m_{\text {coal }}(t) k_{2}(t)$

With carbon $(\mathrm{t})$ the coal mass has not yet reacted at time $\mathrm{t}$.

The devolatilisation of the mass fraction at time $\mathrm{t}$ is written:

$W=\frac{1}{m_{o}} \int_{0}^{t}\left(\alpha_{1} k_{1}+\alpha_{2} k_{2}\right) m_{\text {coal }}(t) d t$ 
Where $m_{o}$ is the initial mass of the sample $(\mathrm{kg})$.The mass of carbon $m_{\text {coal }}(t)$ present at a time $\mathrm{t}$ is:

$m_{\text {coal }}(t)=m_{o} e^{-\int_{0}^{t}\left(\alpha_{1} k_{1}(t)+\alpha_{2} k_{2}(t)\right) d t}$

The devolatilisation of the fraction at the instant $\mathrm{t}$ is thus written:

$W=\int_{0}^{t}\left(\alpha_{1} k_{1}+\alpha_{2} k_{2}\right) e^{-\int_{0}^{t}\left(\alpha_{1} k_{1}(t)+\alpha_{2} k_{2}(t)\right) d t}$

Knowing that $\alpha_{2}>\alpha_{1}$, it is necessary that the speed of the reaction of Eqn. R2 increases more strongly with the temperature than that of the reaction of Eqn. R1. This requires imposing the condition $E_{2}>E_{1}$. The thermal history of the particle during its fall is then taken into account.

The rate constants $k_{1}$ and $k_{2}$ are a function of time via temperature (Arrhenius laws). All reactions obey Arrhenius's law as follows;

$k_{i}=A_{i} e^{-\frac{E_{i}}{R T}}$

With $\mathrm{k}$ the speed constant $\left(\mathrm{s}^{-1}\right)$, A is the pre-exponential factor $\left(\mathrm{s}^{-1}\right), \mathrm{E}$ is the energy of activation $\left(\mathrm{kJ} \mathrm{mol}^{-1}\right), \mathrm{R}$ is the perfect gas constant $\left(\mathrm{R}=8.314 \mathrm{~J} \mathrm{~mol}^{-1} \mathrm{~K}^{-1}\right)$, and $\mathrm{T}$ is the temperature of the particle $(\mathrm{K})$.

The heating of the particle during its movement in the reaction zone is calculated from the heat balance:

$\frac{d T}{d t}=\frac{3}{\rho C_{p} L}\left(\varepsilon \sigma\left(T_{\text {wall }}^{4}-T^{4}\right)+h\left(T_{\text {gas }}-T\right)\right)$

Where $\rho$ is the density of the particle $\left(\mathrm{kg} \mathrm{m}^{-3}\right), \mathrm{Cp}$ is the heat capacity of the particle $\left(\mathrm{Jmol}^{-1} \mathrm{~kg}^{-1}\right), \mathrm{L}$ is the radius of the particle $(\mathrm{m}), \varepsilon$ is the emissivity of the particle solid, $\sigma$ Boltzmann constant $\left(\mathrm{W} \mathrm{K}^{-4} \mathrm{~m}^{-2}\right)$ and $\mathrm{h}$ is the external coefficient of heat transfer ( $\mathrm{ms}^{-}$ $\left.{ }^{2}\right)$.

2. Biomass Pyrolysis

Lignocellulose biomass pyrolysis has been described by kinetic models of different complexities. Depending on the type of reaction scheme chosen, three classifications can be noted [36]:

- Global one-step models and one-step global reaction.

- Single-step models and multiple reactions (one-stage, multi-reaction models).

- Semi-global models with two or more stages (semi-global models).

\section{SRM model}

The single reaction model (SRM) has been proposed to extract the kinetic constants for fast pyrolysis of wood [37]. The devolatilization of the particles is taken into account according to a single global reaction. This model tracks the evolution of total gas and 
tar yields during pyrolysis, in contrast to other simple models [38] where the formation of these two products is taken into account by two parallel reactions.

The final decomposition of biomass in the reactor, unlike coal, does not depend on the temperature (in the field studied). A single reaction can be enough to describe its pyrolysis:

$\mathrm{CH}_{x} \mathrm{O}_{y} \rightarrow \alpha_{1} \mathrm{CH}_{x 1} \mathrm{O}_{y 1}+\left(1-\alpha_{1}\right) C_{\text {char }}$

This model is a simplification of the kinetic scheme proposed by Kobayashi [26]. The same assumptions, equations and parameters of the model are used, as well as the same procedure for calculating and optimizing the kinetic parameters. The density of wood is not calculated but taken from literature, which is $655 \mathrm{~kg} \mathrm{~m}^{-3}$, according to Reschmeier and Karl, 2016 [39].

The fraction devolatilized at time $\mathrm{t}$ is written:

$W_{b}=\int_{0}^{t}\left(\alpha_{1} k\right) e^{-\int_{0}^{t}\left(k_{1}(t)\right) d t}$

\section{IPR model applied to biomass decomposition}

With the IPR (Independent Parallel Reaction) model, the lignocellulosic structure of biomass is modeled by each of its components: cellulose, hemicellulose and lignin. These three components degrade independently. The decomposition reactions are thus independent and parallel [40-42]. The main parameters and equations of this model are as follows:

- The initial mass of the sample is presented as follows:

$m_{\text {initial }}=m_{o}+m_{\text {char }}+m_{\text {hum }}+m_{\text {ash }}$

Where $m_{o}$ is the maximum mass of volatiles released, $m_{c h a r}$ is the mass of the carbon residue produced by the complete devolatilization of the volatile matter from the sample, $m_{a s h}$ is the mass of ash contained in the sample and $m_{\text {hum }}$ is the mass humidity.

- For the IPR model, only the variation of $m_{o}$ minus the part of the sample that devolatilizes is considered.

At time $t$, the mass of the sample remaining to be decomposed is the sum of the masses of the three remaining components: hemicellulose $(\mathrm{H})$, cellulose $(\mathrm{C})$ and lignin $(\mathrm{L})$. It is calculated by:

$m(t)=\sum_{i=H, C, L} m_{i}(t)=\sum_{i=H, C, L}\left(m_{i}(0)-m_{v o l, i}^{e}(t)\right.$

Where:

$m_{i}(0)$ is the initial mass of each component $\mathrm{i}(\mathrm{i}=\mathrm{H}, \mathrm{C}, \mathrm{L}) . m_{i}(0)=\alpha_{i} m_{0}$.

$\alpha_{i}$ is the fraction of volatiles produced by each component i $\left(\sum \alpha_{i}=1\right)$. 
$m_{i}(t)$ is the mass of component $i$ at time $(\mathrm{t})$.

$m_{v o l, i}^{e}(t)$ is the mass of volatiles generated by the devolatilization of component $i$ at time $(\mathrm{t})$.

Several hypotheses have been proposed to simplify the model:

- The devolatilization reaction is of order 1 for each component.

$T(t)$ is the temperature of the sample at time $(t)$. It evolves linearly as a function of time:

- The kinetic parameters $k_{i}(T(t))$ obey the Arrhenius law, such that:

$$
k_{i}(T(t))=A_{i} e^{\left(-\frac{E \alpha_{i}}{R T(t)}\right)}
$$

- The overall reaction that presents the total mass loss is as follows:

$$
\frac{d m}{d t}(t)=\sum_{i=H, C, L} k_{i}(T(t))\left(m_{i}(0)-m_{v o l, i}^{e}(t)\right)
$$

The mass balances for the gas mixture (including the tar vapors, the non-condensable gases and inert gas) are:

$$
\underbrace{\frac{\partial\left(\varepsilon \rho_{\text {mixtures }}\right)}{\partial t}}_{\text {accumulation term }}+\underbrace{\nabla \cdot\left(u_{\text {mixture }} \rho_{\text {mixture }}\right)}_{\text {convective term }}=\underbrace{\left(k_{t}+k_{g}\right) \rho_{w}-k_{c 1} \varepsilon \rho_{t}-\theta k_{c 2} \varepsilon \rho}_{\text {source term }}
$$

The transport equations for the tar vapors and non-condensable gases inside the particle pores are:

$$
\underbrace{\frac{\partial\left(\varepsilon \rho_{t}\right)}{\partial t}}_{\text {accumulation term }}+\underbrace{\nabla \cdot\left(u_{\text {mixture }} \rho_{t}\right)}_{\text {convective term }}=\underbrace{\nabla \cdot\left(D_{\text {eff.t }} \nabla \rho_{t}\right)}_{\text {diffusive term }}+\underbrace{k_{t} \rho_{w}-\left(k_{c 1}+k_{g 1}\right) \varepsilon \rho_{t}-\theta\left(k_{c 2}+k_{g 2}\right) \varepsilon \rho_{t}}_{\text {source term }}
$$

$$
\underbrace{\frac{\partial\left(\varepsilon \rho_{g}\right)}{\partial t}}_{\text {accumulation term }}+\underbrace{\nabla \cdot\left(u_{\text {mixture }} \rho_{g}\right)}_{\text {convective term }}=\underbrace{\nabla \cdot\left(D_{e f f, t} \nabla \rho_{g}\right)}_{\text {diffusive term }}+\underbrace{k_{g} \rho_{w}-\left(k_{c 1}+k_{g 1}\right) \varepsilon \rho_{t}+\theta\left(k_{c 2}+k_{g 2}\right) \varepsilon \rho_{t}}_{\text {source term }}
$$

Here, $D_{\text {eff } f_{\text {.t }}}$ is the effective diffusivity $\left(\mathrm{m}^{2} \mathrm{~s}^{-1}\right)$ of tar and non-condensable gases in the particle pores, $k_{t}$ and $k_{g}$ are the reaction rates $\left(\mathrm{s}^{-1}\right)$ of tar product and non-condensable gas, respectively. $k_{c 1}$ and $k_{c 2}$ are the reaction rates $\left(\mathrm{s}^{-1}\right)$ of primary and secondary char, $\theta$ mass fraction of char in the solid phase.

\section{Computational model set up}

The fast pyrolysis reactor $\left(150 \mathrm{~g} \mathrm{~h}^{-1}\right)$ at Aston University is shown in Fig. 3. Nitrogen flows through a porous plate with a temperature of $773 \mathrm{~K}$ and velocity of $U_{0}=1.2 \mathrm{~m} / \mathrm{s}$ at the bottom of the reactor. The particle with $0 \mathrm{~m} / \mathrm{s}$ velocity is injected into the reactor and heat is convected to the surface. The particle degrades to char, gas and tar due to conduction along the particle radius [43]. The specific heat capacity and thermal conductivity of the particle are computed proportionally due to the presence of solids 
(char and wood). Nitrogen with a velocity of $1.2 \mathrm{~m} / \mathrm{s}$ is smaller than the terminal velocity of the particle, which in these conditions is approximately $\approx 1.6 \mathrm{~m} / \mathrm{s}$. Thus, the initial simulation's parameters were that the gravitational force would be greater than the drag force spent on the particle from the surrounding fluid [43].

Based on Bridgwater [44], the most suitable biomass particle sizes for fast pyrolysis are between $100-6000 \mu \mathrm{m}$, with a pyrolysis temperature, between 700 and $800 \mathrm{~K}$ for maximum liquid yield. In this study, the chosen biomass particle diameter was $500 \mu \mathrm{m}$. The particle is injected into the reactor at a temperature of $303 \mathrm{~K}$ and directly exposed to convective heat transfer from nitrogen, which is modelled based on the correlation of Ranz-Marshall [45, 46].

The particle density decreases as a result of devolatilization reactions, which results in char entrainment out of the reactor. The particle density drop during the pyrolysis process is a significant parameter as the drag force tries to overcome gravity. The coal sample used was Chinese brown coal called Zhundong brown coal, and Beechwood was used as the biomass. The proximate and ultimate analysis for coal and Beechwood are shown in Table 1.

Table 1- Elemental composition of the beechwood and coal feedstock.

\begin{tabular}{|c|c|c|}
\hline & Beechwood & Coal \\
\hline \multicolumn{3}{|c|}{ Proximate analysis (wt. $\%$ wet basis) } \\
\hline Volatiles & 77.81 & 30.86 \\
\hline Fixed carbon & 21.24 & 64.79 \\
\hline Ash & 0.95 & 4.34 \\
\hline \multicolumn{3}{|c|}{ Ultimate analysis (wt. \% wet basis) } \\
\hline $\mathrm{N}$ & 0.1 & 1.19 \\
\hline $\mathrm{C}$ & 49.66 & 75.39 \\
\hline $\mathrm{H}$ & 6.29 & 3.48 \\
\hline $\mathrm{O}$ & 43.95 & 15.19 \\
\hline$S$ & - & 0.42 \\
\hline Empirical formula & $\mathrm{CH}_{1552} \mathrm{O}_{0664} \mathrm{~N}_{0002}$ & $\mathrm{CH}_{0.554} \mathrm{O}_{0.151} \mathrm{~N}_{0.014} \mathrm{~S}_{0.002}$ \\
\hline
\end{tabular}

The geometry of the fluidized bed reactor is $40 \mathrm{~mm}$ wide and $260 \mathrm{~mm}$ high. The geometrical domain of the freeboard is divided into a grid (mesh) that has a number of small cells [47]. The grid design is essential in a numerical simulation because it has a significant impact on the rate of convergence, solution accuracy and CPU time required [48]. The appropriate grid size is required to achieve a reasonable compromise between the competing needs for calculation accuracy and manageable computational times [47]. 


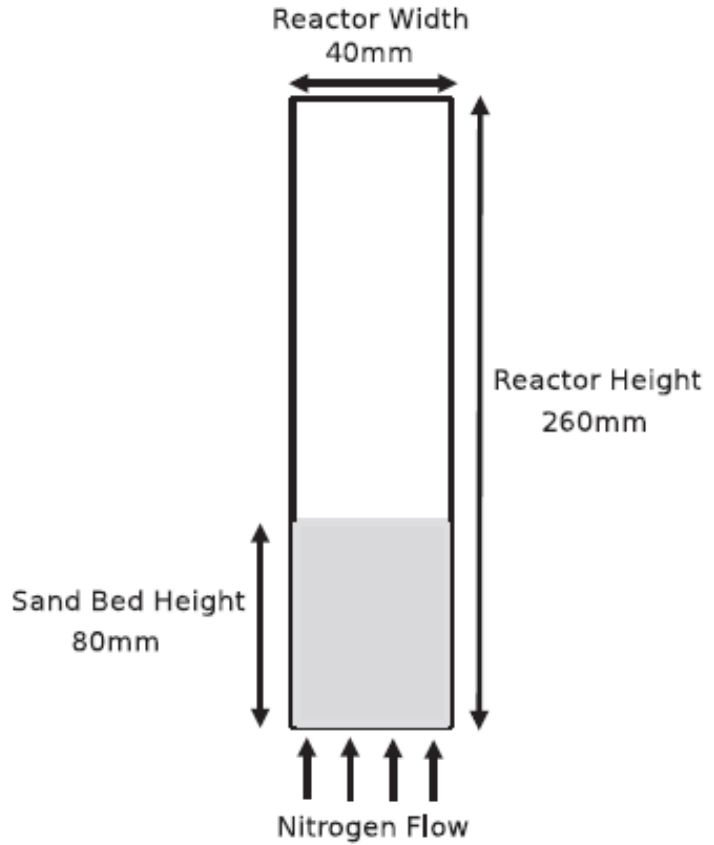

Fig. 3 Fluidized bed reactor.

The mesh must be chosen to be able to effectively capture the hydrodynamics inside the freeboard of the fluidized bed reactor [34]. Several simulation trials were carried out to examine the mesh sensitivity and ensure that the solution accuracy is independent of grid size. The optimal grid size (uniform Cartesian grid of 420 quadrilateral cells) has been chosen for the freeboard geometrical domain. It was found that the optimized cell size $(10 \mathrm{~mm} \times 10 \mathrm{~mm})$ equals about 3 times larger than the particle diameter. Consistent with the literature, the mesh size of such scale is suitable for solid-gas CFD simulations and sufficient to resolve the gas-particle flow [49].

Based on Thiele modulus, the reaction of the solid particle size should be described by either the shrinking core or the reactive core method [50]. Thiele modulus $T h$ gives the relationship of kinetic to the diffusion time scale. For the response number $n=1$, the definition is as follows [51]:

$T h=l_{p} \sqrt{\frac{k}{D_{p} r}}$

In which $k$ is the reaction rate constant, $l_{p}$ the characteristic length of the particle, $D p$ the diffusion coefficient of the particle and $r$ is the hydraulic radius of the pores. If $T h<1$, a shrinking core regime is found. Heterogeneous reactions happen on the surface, and the gaseous reactants do not diffuse into the solid particle. For $T h>1$ the reacting core regime is defined. In this regime, gaseous reactants diffuse into the particle, and volumetric reactions are observed in the solid [49].

During the devolatilisation process, the particle shrinkage is significantly affected by the following swelling coefficient equation: 
$\frac{d_{p}(t)}{d_{p, 0}}=1+\left(C_{S w}-1\right) \frac{\left(1-M C_{0}\right) m_{p, 0}-m_{p}}{V M_{0}\left(1-M C_{0}\right) m_{p, 0}}$

Here $M C_{0}$ is the initial moisture content of the biomass and $V M_{0}$ is the initial volatile matter content of the studied solid particles, obtained from the proximate analysis. The term $\frac{\left(1-M C_{0}\right) m_{p, 0}-m_{p}}{V M_{0}\left(1-M C_{0}\right) m_{p, 0}}$ is the ratio between the total volatile mass and the devolatilisation mass of the particle.

During the devolatilization process, the size of the particle is determined by the swelling coefficient. If the value of the swelling coefficient is more than 1 , the size will increase, and when the value of the swelling coefficient is less than 1, the size will be reduced. For example, if the value of the swelling coefficient is changed to 2.0, the effect is twice as much. In addition, the expansion number is obtained by a formal analysis and can be calculated by the following equation:

$C_{s w}=\frac{d_{p}}{d_{p_{o}}}$

where $d_{p}$ is the average diameter of the particles, and $d_{p o}$ is the average diameter of the parent fuel.

According to the morphological results, the value of the swelling factor of the studied biomass is 0.7. As a result, it is more and more challenging to measure actual results. As far as this work is concerned, the range of $0.5 \leq 1$ is considered uncertain. The carbon oxidation rate is predicted by the following equation [38]:

$\frac{d m_{p}}{d t}=A_{p} k\left(P_{O_{2}, \infty}-\frac{d m_{p}}{d t} \frac{1}{s_{p} D}\right)^{n}$

where $m_{p}$ is the mass of the particle, $\mathrm{A}_{p}$ is the external surface area of the particle which is calculated according to the particle size $\mathrm{d} p, P_{O_{2}, \infty}$ is the oxygen partial pressure, $\mathrm{n}$ is the apparent reaction order, $k$ is the apparent kinetic rate, and $D$ is the external diffusion rate coefficient calculated as follows [52]:

$k=A_{a} \exp \left(-\frac{E_{a}}{R T}\right)$

$D=2.57 \times 10^{-7} \frac{\left[\left(T_{p}+T_{\infty}\right) / 2\right]^{0.75}}{d_{p}}$

In addition to drying, pyrolysis and char oxidation reactions, the homogeneous gas reaction can also be detected in the fuel bed. According to the hypothesis of the model system and the bed model, the homogeneous gas reaction is described in the modelling method. The homogeneous gas reaction should include the oxidation of the gas produced from pyrolysis and the reaction between the gas product from the thermal solution and product from pyrolysis.

Validation 
As mentioned above, there is little contribution for verification because of the need for different input variables that are usually not completely given. On the other hand, if one or more parameters (such as biochemical composition) are taken from another source, the value of verification is limited.

Compared with Zhang et al., [53] two raw materials, leguminous straw and Dayan lignite were selected for the study in which co-pyrolysis reactions are carried out in a agreement with the experimental data for the reaction temperature $500^{\circ} \mathrm{C}$ for all blend ratios (biomass/coal).

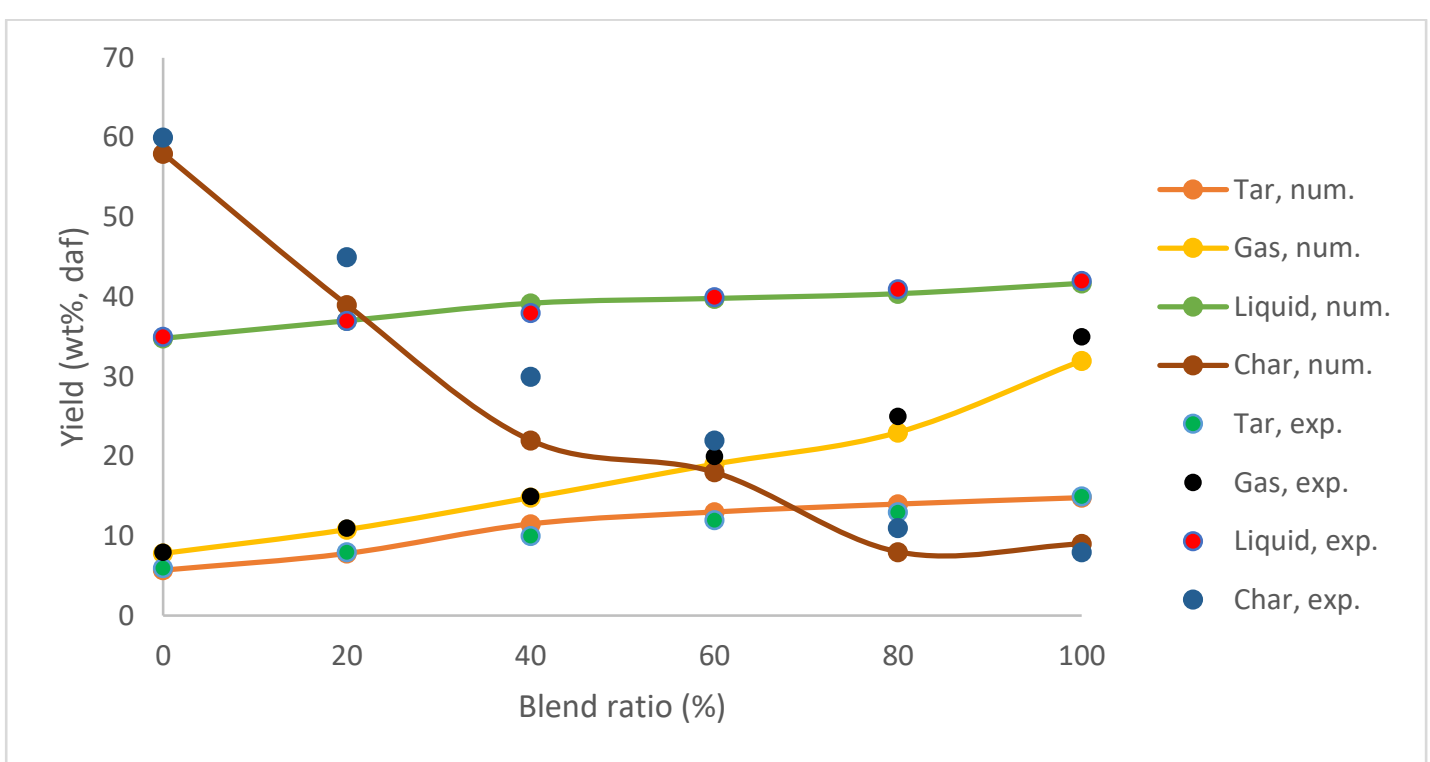

Fig. 4 Comparison between experimental and numerical yields produced during co-pyrolysis of biomass blends at $500^{\circ} \mathrm{C}$.

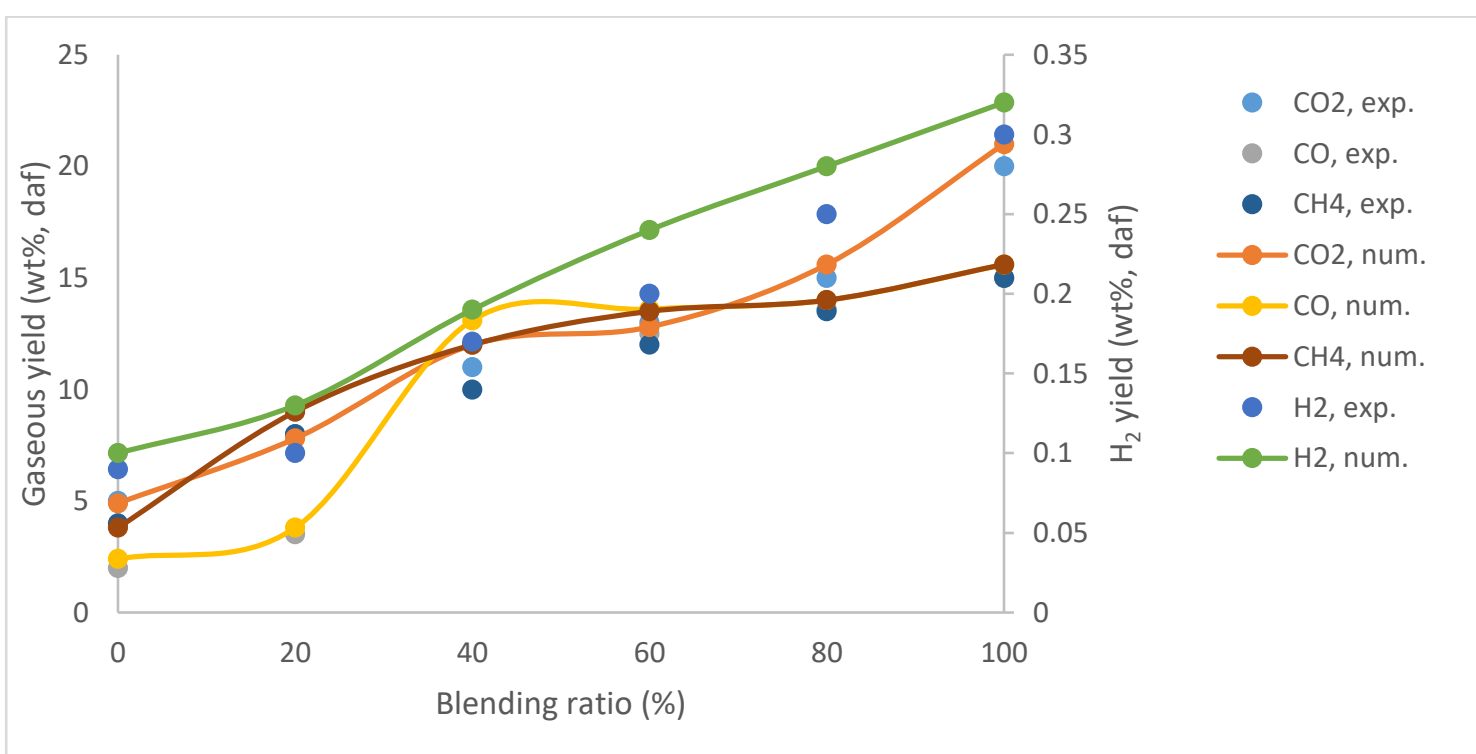

Fig. 5 Comparison between experimental and numerical for gas produced during co-pyrolysis of biomass blends at $500^{\circ} \mathrm{C}$. 
Compared with Huang et al. [54], the measured tar, char and gas from the co-pyrolysis of coal and biomass, moreover, the gas produced during the pyrolysis of blended fuel is in good agreement with the presented model. Huang et al. conducted co-pyrolysis in a pressurised fluidized bed reactor. The blend ratio of biomass in the mixture was varied between 0 and $100 \mathrm{wt} \%$, and the temperature range was $550-650{ }^{\circ} \mathrm{C}$ with the pressure under 1.0 MPa.

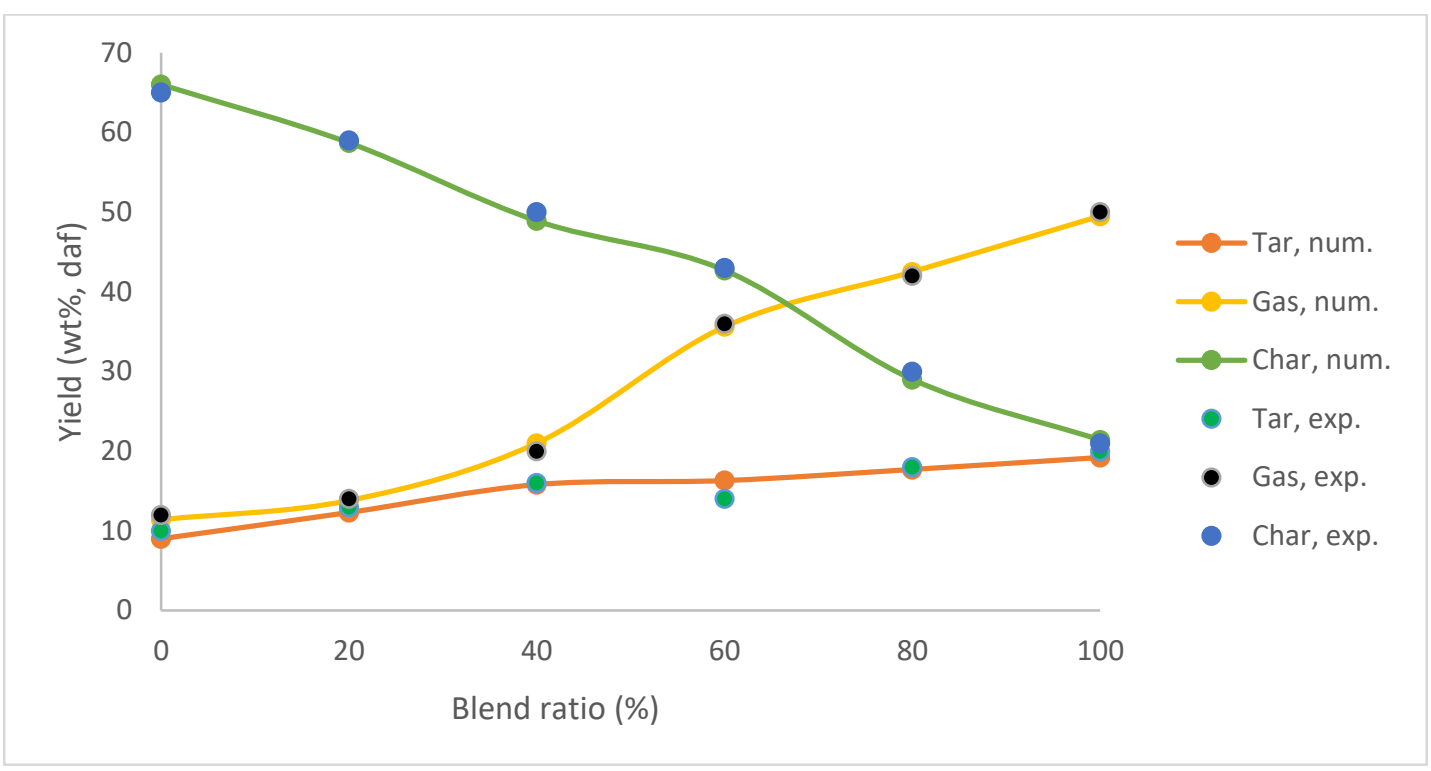

Fig. 6 Comparison between experimental and numerical yields produced during co-pyrolysis of biomass blends at $600^{\circ} \mathrm{C}, 0.3 \mathrm{MPa}, \mathrm{N}_{2}$.

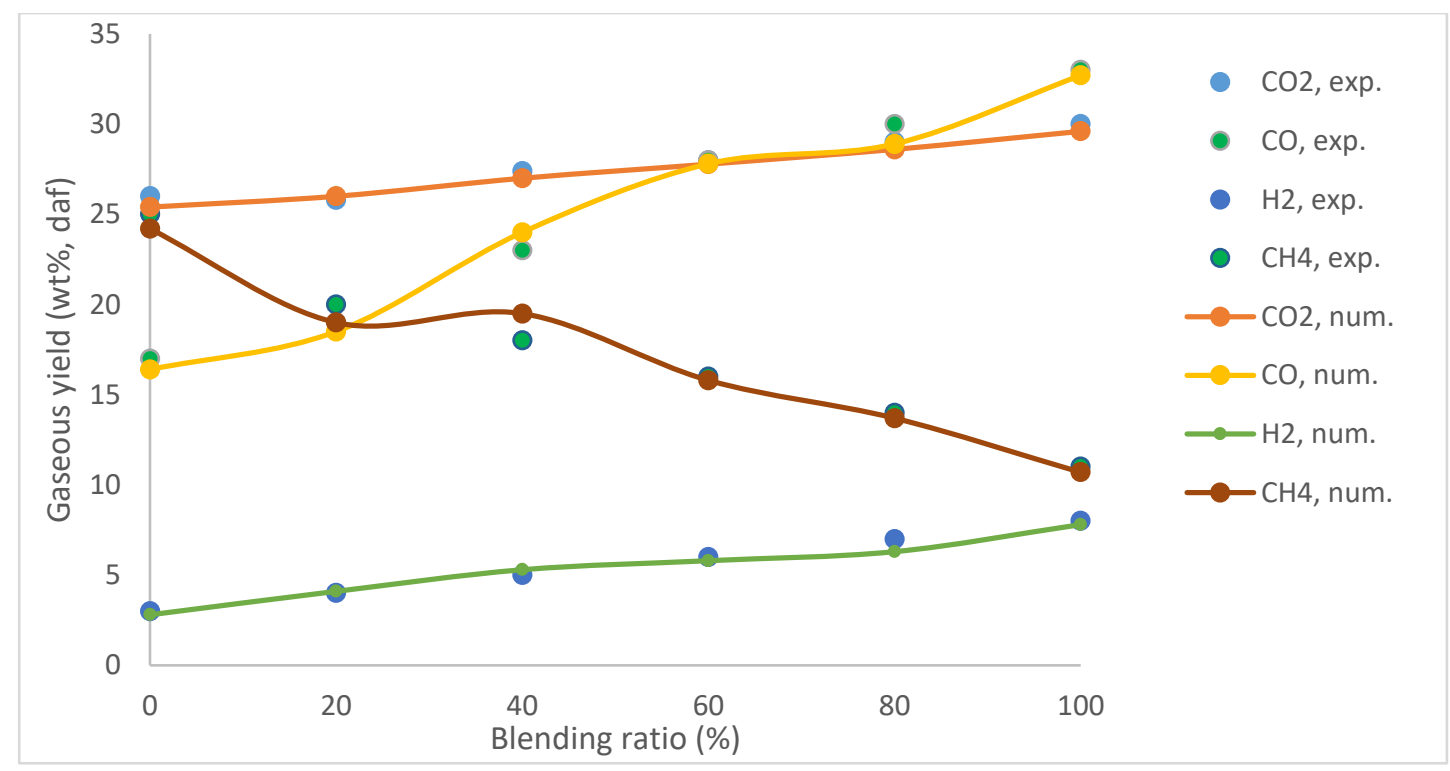

Fig. 7 Comparison between experimental and numerical of gas produced during co-pyrolysis of biomass blends at $600^{\circ} \mathrm{C}, 0.3 \mathrm{MPa}, \mathrm{N}_{2}$.

\section{Results and Discussion}

Based on the Refs. [54- 61], the pyrolysis of biomass or coal is comparable based on the product yields. As fast pyrolysis temperature increases the yield of gas increases 
more significant than that from coal. For coal, the yield of gas increases at higher temperatures approximately $600{ }^{\circ} \mathrm{C}$, and maximum liquid yields are achieved at 600 ${ }^{\circ} \mathrm{C}$, while the yield of tar increases marginally with the increase in temperature.

For the biomass more volatiles (pyrolysis gas + water) are created from the pyrolysis of biomass than that of coal under similar conditions. This is most likely because of the difference in their subatomic structure. The stability of the coal structure, which generally consists of thick polycyclic aromatic ring hydrocarbons connected by $\mathrm{C}-\mathrm{C}$ bonds, is resistant to heat. Biomass consists of a macromolecular structure (cellulose, hemicellulose and lignin) connected generally by weak ether bonds, that can be broken easily at temperatures above $400{ }^{\circ} \mathrm{C}$. Under high heating rate conditions, reactor temperatures strongly affect depolymerization reactions (volatile formation) of biomass $[18,19]$.

Due to weaker bonds in biomass, higher volatile yields and a more hydrogen-rich gas are produced compared to coal. Under similar pyrolysis conditions, the $\mathrm{H}_{2}$ yield (wt.\%, daf) created from biomass is around 5- 16 times higher than $\mathrm{H}_{2}$ yields produced from coal [7]. This shows that biomass could potentially supply $\mathrm{H}_{2}$ for coal pyrolysis [5], bringing about specific synergies during the co-pyrolysis of biomass and coal.

The effects of blending ratio on the yields of liquid, char and gaseous components generated from co-pyrolysis over the temperature range of $500-700^{\circ} \mathrm{C}$ are represented in Figs. 8- 10. Figs. 8- 10 show the yields of liquid, char and gaseous produced from the co-pyrolysis of biomass and coal for range temperature of $500-700^{\circ} \mathrm{C}$. It has been shown that the blending of biomass with coal affects the yield of pyrolysis products (liquid and gas).

A higher ratio of blending results in increased yields of gas and liquid, while char and tar yields decrease. Especially at $600{ }^{\circ} \mathrm{C}$ and the blending ratio of biomass to coal of 74 wt. $\%$, reducing char yields by $14 \%$ and increasing liquid yields by $10 \%$. Fig. 8 additionally shows some comparable outcomes at $500{ }^{\circ} \mathrm{C}$, the higher blending proportion (for example $74 \mathrm{wt} . \%$ and $75 \mathrm{wt} . \%$ ) prompts lower yields of char (decline by about 5\%) and higher yields of liquid (increase by about 5\% and 7\%, respectively). As discussed, the identified synergies happen at higher blending ratios which more hydrogen, resulting in the hydrogenation of coal pyrolysis, resulting in positive synergetic effects during the co-pyrolysis of biomass and coal.

Also, the reactor temperature affects the synergies between biomass and coal during co-pyrolysis. In Figs. 8- 10, there are evident synergetic impacts in the co-pyrolysis at $500{ }^{\circ} \mathrm{C}$ and $600{ }^{\circ} \mathrm{C}$ compared to $700{ }^{\circ} \mathrm{C}$. Liquid yield for biomass pyrolysis diminishes with increasing temperature, while the maximum liquid yield for coal pyrolysis occurs at $600{ }^{\circ} \mathrm{C}$. So it can be concluded that at $600{ }^{\circ} \mathrm{C}$ recognizable synergies occur in the copyrolysis of biomass and coal, due to sufficient radical pyrolysis elements produced from coal and hydrogen-contributors produced from biomass at this temperature. Researchers also found that in TGA experiments, with the increase of biomass [62- 66]. The evidence of the above results is shown in Figs 8-10, showing the variation of liquid, gas and char yields produced from different biomass ratios. 


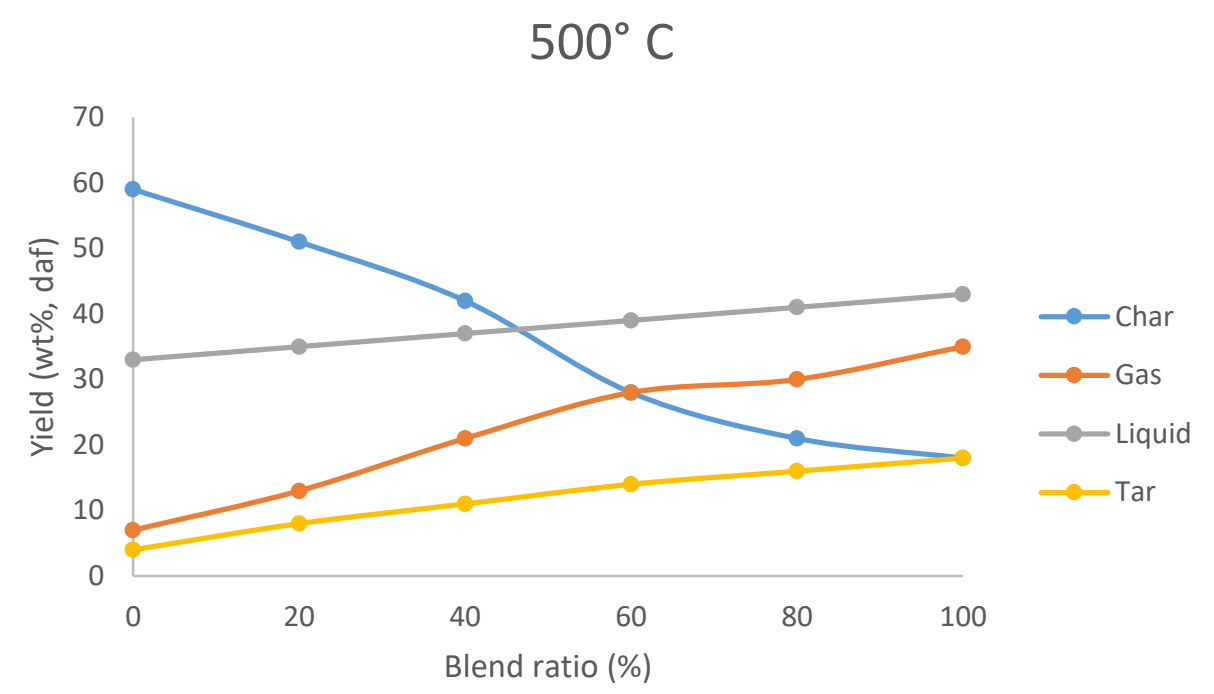

Fig. 8 Numerical results for product yields from co-pyrolysis of biomass blends at $500^{\circ} \mathrm{C}$.

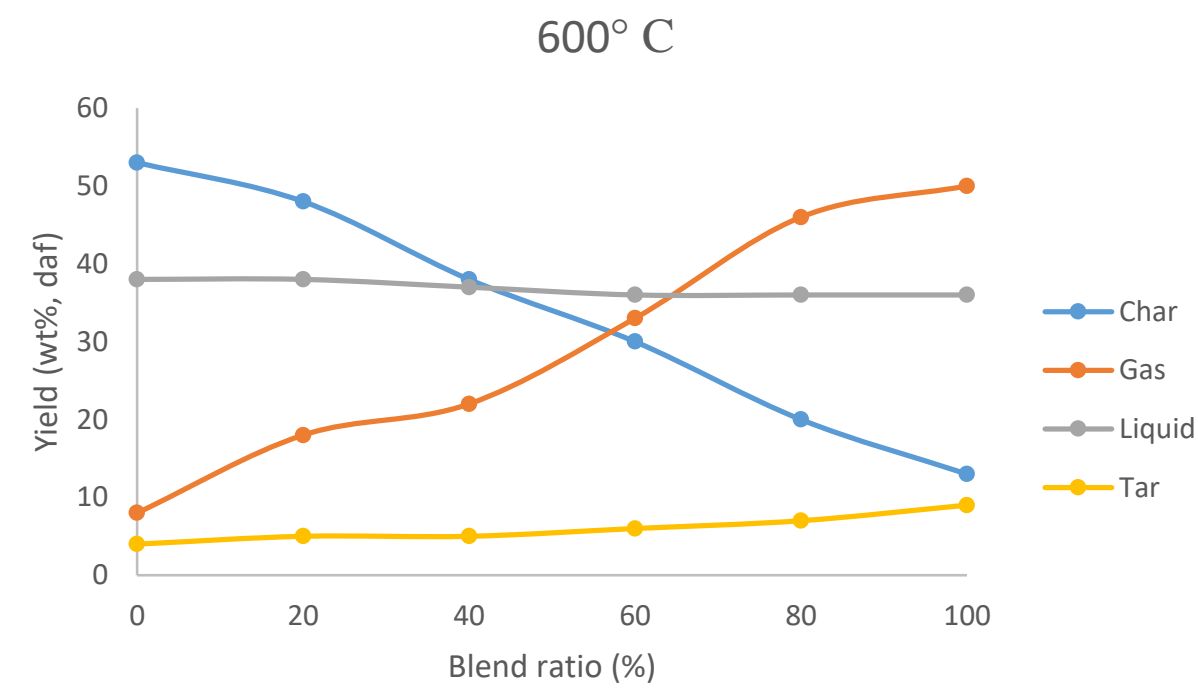

493

Fig. 9 Numerical results for product yields from co-pyrolysis of biomass blends at $600^{\circ} \mathrm{C}$. 


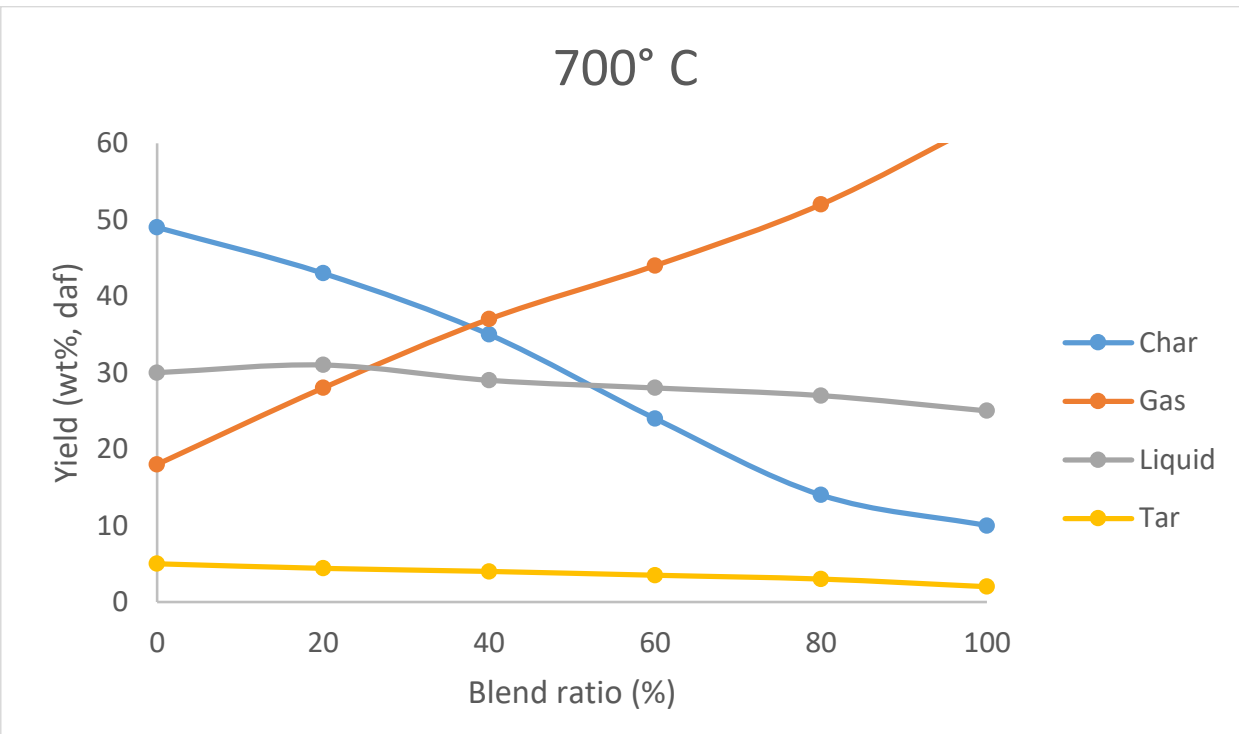

Fig. 10 Numerical results for product yields from co-pyrolysis of biomass blends at $700^{\circ} \mathrm{C}$.

Figs. 11- 13 show that at higher blending ratios, the yields of char are lower than the yields of liquid and tar. Moreover, the gaseous yields of $\mathrm{CH}_{4}$ is high relatively than $\mathrm{CO}, \mathrm{CO}_{2}$ and $\mathrm{H}_{2}$ over the entire blending proportion run, as appeared in the results. As the numerical results showed, the highest $\mathrm{H}_{2}$ yield was seen at $600{ }^{\circ} \mathrm{C}$ compared to $\mathrm{H}_{2}$ yields produced at $500{ }^{\circ} \mathrm{C}$ and $700{ }^{\circ} \mathrm{C}$. Suggesting that the fast pyrolysis temperature of $600{ }^{\circ} \mathrm{C}$ is more suitable for generating hydrogen for pyrolysis radicals produced from coal and subsequently increasing liquid yields. More significantly, the yields of volatiles produced from the co-pyrolysis of biomass and coal are higher than the usually determined quantities of the separate fuel, especially increasing by over $8 \%$ at $600{ }^{\circ} \mathrm{C}$.

Synergetic impacts on char yields in the co-pyrolysis of biomass and coal were observed. Char yields are lower than the theoretical yields determined on pyrolysis of each fuel at higher blending ratios. It was discovered that some synergetic consequences for char reactivity happen during the co-pyrolysis of biomass and coal. Char from co-pyrolysis would be believed to be composed to be majority made up of coal char under similar conditions, regardless of the lower yields of char from the copyrolysis than what might be epected. The reactivity of the char from co-pyrolysis at the lower blended ratio (around $30 \mathrm{wt} \%$ ) is similar to char produced from coal pyrolysis [55]. The reactivities of the char from co-pyrolysis at higher blended ratios (around $70 \mathrm{wt} . \%$ ) are averaging about 2.3 times higher than char produced from coal pyrolysis, and much higher than char produced from biomass pyrolysis [60]. 


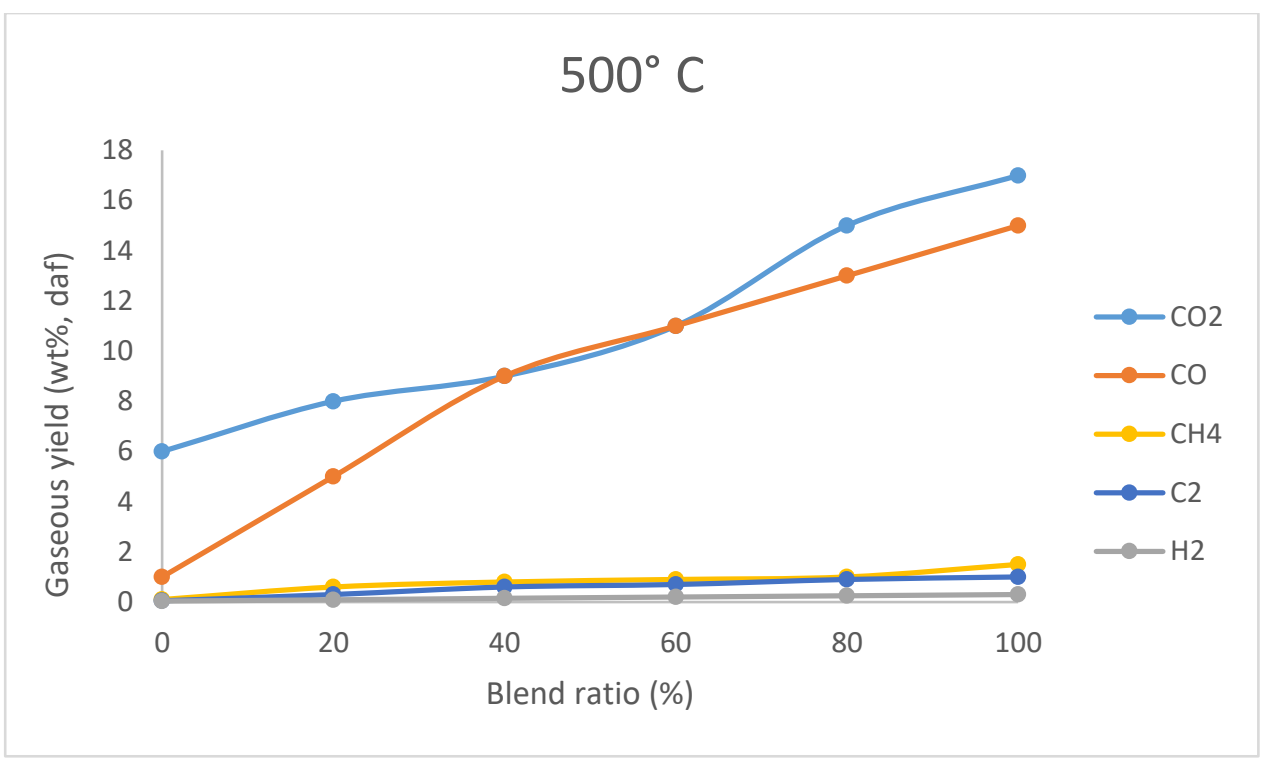

Fig. 11 Numerical results for gas yields during co-pyrolysis of biomass blends at $500^{\circ} \mathrm{C}$.

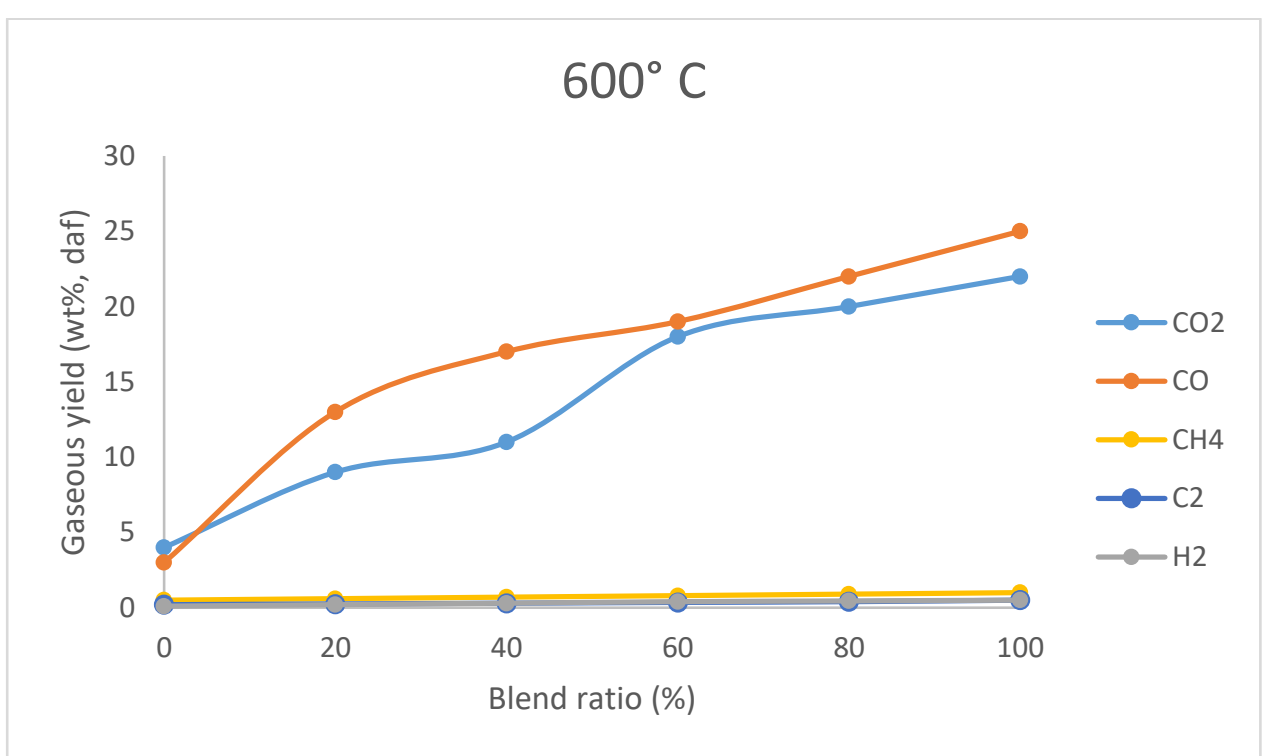

Fig. 12 Numerical results for gas yields during co-pyrolysis of biomass blends at $600^{\circ} \mathrm{C}$. 


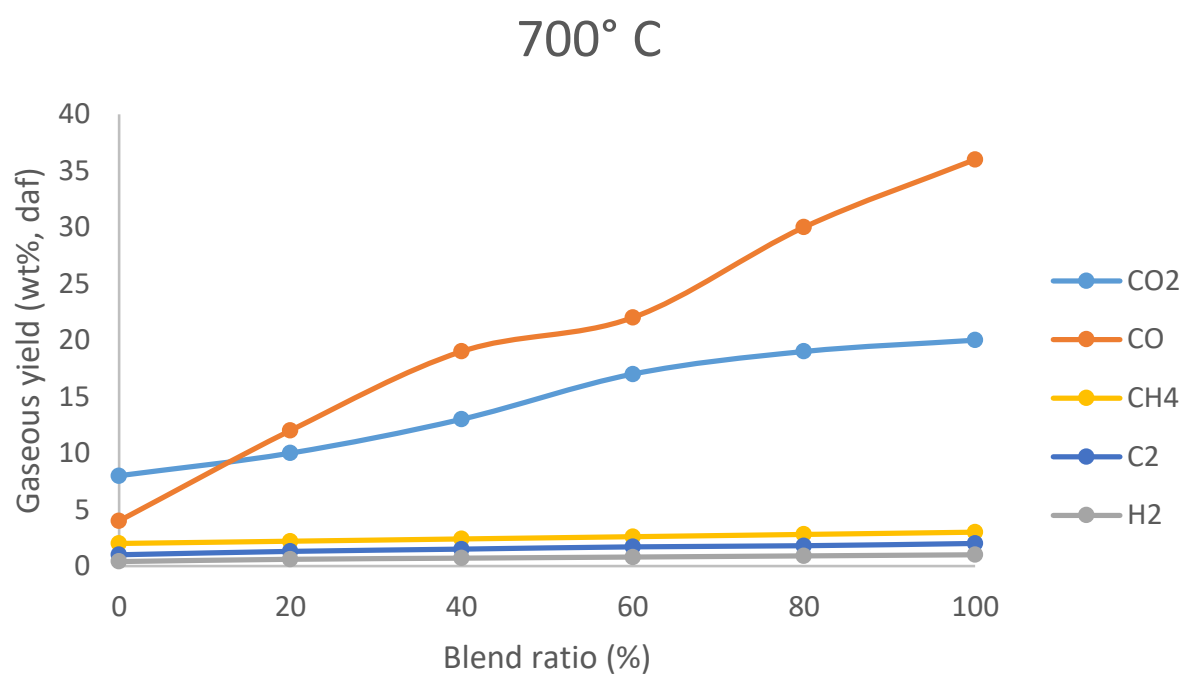

Fig. 13 Numerical results for gas yields during co-pyrolysis of biomass blends at $700^{\circ} \mathrm{C}$.

As mentioned, the synergy effect is generally achieved at higher biomass to coal ratios; this may be due to the need for a sufficient amount of biomass to provide an abundant supply of hydrogen. This results in some obvious effects in co-pyrolysis of biomass and coal, identifying that the amount of hydrogen supplied from biomass has a crucial role in coal pyrolysis [5]. The reactivity of the char is improved during the synergetic co-pyrolysis of biomass and coal in the fluidized bed; however, the char reactivity is reduced with increased reactor temperatures.

Pyrolysis characteristics of three different blend ratios (biomass/coal $=70: 30,50: 50$ and 30: 70) were studied. All biomass particles have similar initial volume and initial masses. From Figs 14 and 15, it can be seen that with an increased percentage of biomass the temperature of the blended feed increases after $\sim 60$ seconds. The pyrolysis rate also increases with an increased biomass fraction. 


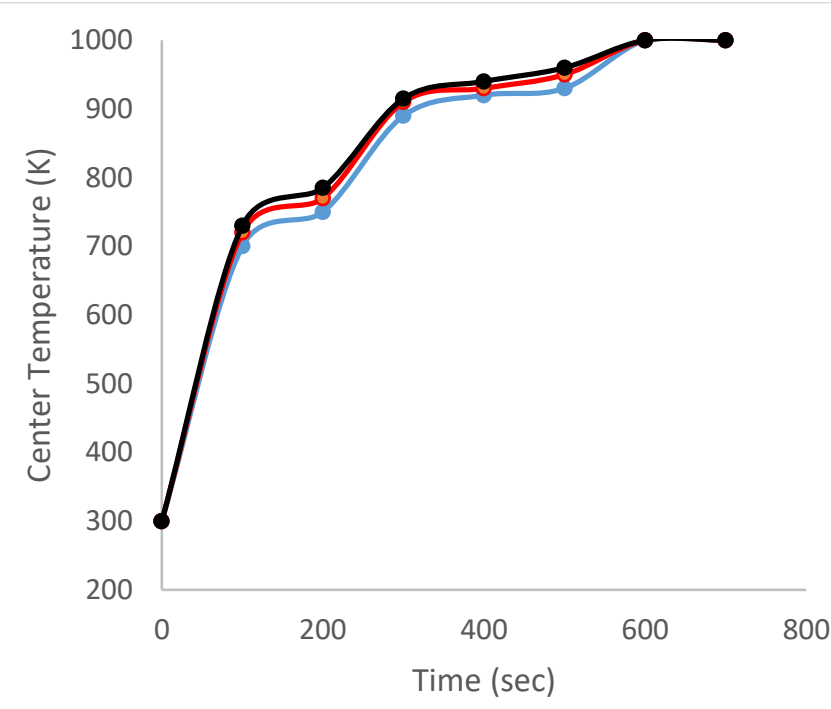

$\longrightarrow$ 70: 30 blend ratio

$\multimap-50: 50$ blend ratio

$\longrightarrow$ 30: 70 blend ratio

Fig. 14. Numerical results of the center temperature of blended fuel particles under different blend ratios.

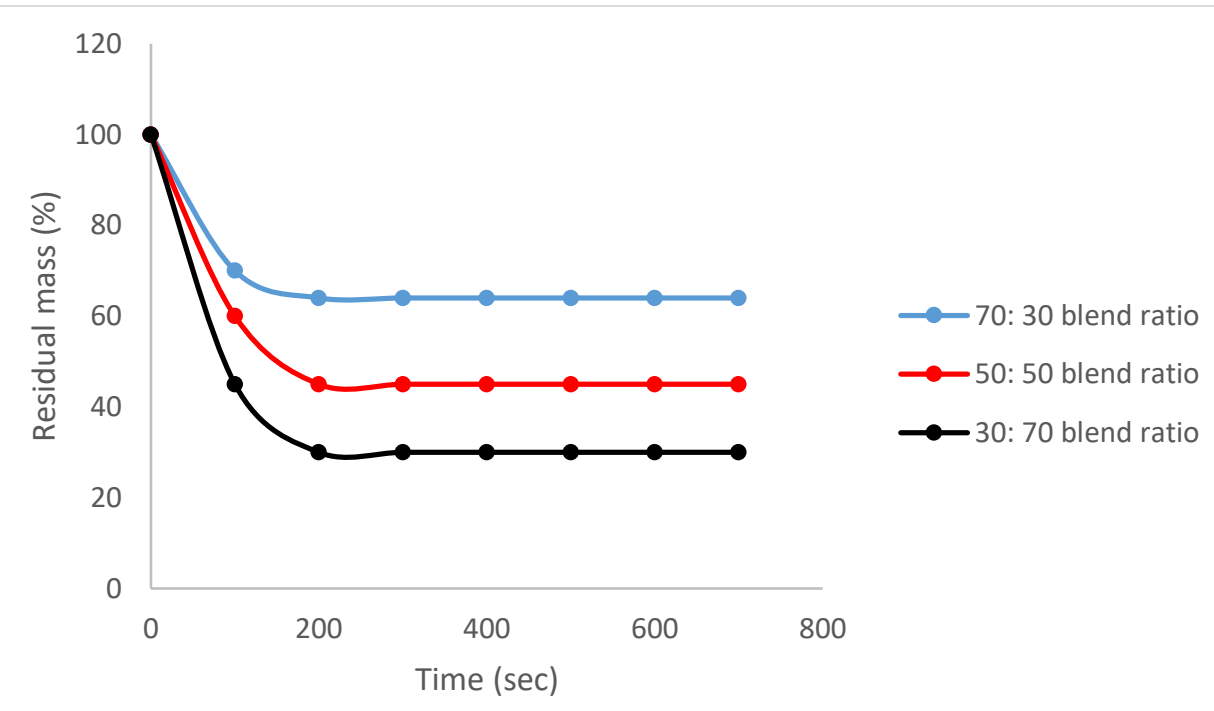

Fig. 15. Numerical results of the residual mass of blended fuel particles under different blend ratios.

\section{Conclusion}

Pyrolysis is a very complex phenomenon that usually precedes the step of heterogeneous combustion. It is always confused with the devolatilization (release of volatile matter under the effect of heat). Based on the literature review for the copyrolysis of biomass and coal, a mathematical model is to model co-pyrolysis systems to explore the synergetic effects of co-pyrolysis of biomass and coal.

The present model allowed for the simulation and analysis of pyrolysis of solid particles. The results obtained in the case of the co-pyrolysis show a good agreement with the experimental results. Also, the results found by the present model are more satisfactory for biomass and coal blended at different ratios. 
Co-pyrolysis of beech wood and Zhundong brown coal are carried out in a fluidized bed reactor working under a numerical model, and the effects of blending ratio and fast pyrolysis temperature on the synergy between biomass and coal were studied. The results show that the char yields decrease, and the liquid and gas yield increase, even the blended species do not produce similar product yields compared to each feedstock separately, indicating that there is a synergetic effect between biomass and coal under certain conditions.

The most significant degree of synergetic effects on the product yields was observed at $600^{\circ} \mathrm{C}$ and a biomass blending ratio of $70 \mathrm{wt} . \%$. It can be concluded that both the higher blending ratio and the relatively lower temperature are more in favour of synergies between biomass and coal during co-pyrolysis in a fluidised bed reactor. Furthermore, the improvement of char reactivity also identifies the synergies in co-pyrolysis.

The synergistic effect between coal and biomass in the co-pyrolysis prove that it can produce higher char conversion and higher liquid product yield compared to the individual biomass and coal. Also, the co-pyrolysis model of the blend can be directly derived from the existing pyrolysis model of coal and biomass, which will be beneficial to the co-combustion model of the coal-biomass blend.

\section{Acknowledgments}

This research was funded under the BRISK2 (Biofuels Research Infrastructure for Sharing Knowledge II) project funded by the European H2020-programme under the 2020 research and innovation programme. This work was also supported by EBRI (Energy and Bioproducts Research Insititute), Aston University, UK.

\section{References}

1. Yin, C., and Yan, J. Oxy-fuel combustion of pulverized fuels: Combustion fundamentals and modeling. Appl. Energy 2016; 162: 742-762.

2. Aboyade, A.O., Carrier, M., Meyer, E.L., Knoetze, H., and Görgens, J.F. Slow and pressurized co-pyrolysis of coal and agricultural residues. Energy Convers. Manag. 2013; 65: 198- 207.

3. Ahmad, T., Awan, I.A., Nisar, J., and Ahmad, I. Influence of inherent minerals and pyrolysis temperature on the yield of pyrolyses of some Pakistani coals. Energy Convers. Manag. 2009; 50: 1163-1171.

4. Souza-Santos, M.L. de (2004). Solid Fuels Combustion and Gasification: Modeling, simulation, and equipment operation, CRC Press, New York.

5. Basu, P. (2013). Biomass Gasification, Pyrolysis and Torrefaction: Practical Design and Theory (Academic Press).

6. D. W. Van Krevelen (1993). Coal: Typology-Physics-Chemistry-Constitution. Elsevier Science, Amsterdam, The Netherlands.

7. H. B. Vuthaluru, "Thermal behaviour of coal/biomass blends during co-pyrolysis," Fuel Processing Technology 2004; vol. 85, no. 2-3, pp. 141-155.

8. D. W. Van Krevelen (1993). Coal: Typology-Physics-Chemistry-Constitution. Elsevier Science, Amsterdam, The Netherlands. 
9. Collot A. G., Zhuo Y., Dugwell D. R., and Kandiyoti R. Co-pyrolysis and cogasification of coal and biomass in bench-scale fixed-bed and fluidized bed reactors. Fuel 1999; 78:667-679.

10. Sonobe T., Worasuwannarak N. and Pipatmanomai S. Synergies in co-pyrolysis of Thai lignite and corncob. Fuel Processing Technology 2008; 89:1371-1378.

11. Chatphol $\mathrm{M}$ and Behdad M. Lack of synergetic effects in the pyrolytic characteristics of woody biomass/coal blends under low and high heating rate regimes. Biomass and bioenergy 2002; 23: 55-66

12. Vuthaluru H. B. Thermal behaviour of coal/biomass blends during co-pyrolysis. Fuel processing technology 2004; 85:141-155

13. Zhang, L., Ninomiya, Y., Wang, Q., and Yamashita, T. Influence of woody biomass (cedar chip) addition on the emissions of PM10 from pulverised coal combustion. Fuel 2011; 90: 77-86.

14. D. K. Park, S. D. Kim, S. H. Lee, and J. G. Lee, "Co-pyrolysis characteristics of sawdust and coal blend in TGA and a fixed bed reactor," Bioresource Technology, vol. 101, no. 15, pp. 6151-6156, 2010.

15. C. Chen, X. Ma, and Y. He, "Co-pyrolysis characteristics of microalgae Chlorella vulgaris and coal through TGA," Bioresource Technology, vol. 117, pp. 264-273, 2012.

16. H. Shui, C. Shan, Z. Cai et al., "Co-liquefaction behavior of a sub-bituminous coal and sawdust," Energy, vol. 36, no. 11, pp. 6645-6650, 2011.

17. A. O. Aboyade, J. F. Gorgens, M. Carrier, E. L. Meyer, and J. ' H. Knoetze, "Thermogravimetric study of the pyrolysis characteristics and kinetics of coal blends with corn and sugarcane residues," Fuel Processing Technology, vol. 106, pp. 310$320,2013$.

18. H. Haykiri-Acma and S. Yaman, "Synergy in devolatilization characteristics of lignite and hazelnut shell during co-pyrolysis," Fuel, vol. 86, no. 3, pp. 373-380, 2007.

19. C. A. Ulloa, A. L. Gordon, and X. A. Garc'1a, "Thermogravimetric study of interactions in the pyrolysis of blends of coal with radiata pine sawdust," Fuel Processing Technology, vol. 90, no. 4, pp. 583-590, 2009.

20. O. Onay, E. Bayram, and " O. M. Koc " ukar, "Copyrolysis of " seyitomer-lignite and safflower seed: influence of the blending " ratio and pyrolysis temperature on product yields and oil characterization," Energy and Fuels, vol. 21, no. 5, pp. 3049-3056, 2007.

21. T. Sonobe, N. Worasuwannarak, and S. Pipatmanomai, "Synergies in co-pyrolysis of Thai lignite and corncob," Fuel Processing Technology, vol. 89, no. 12, pp. 1371-1378, 2008.

22. L. Zhang, S. Xu, W. Zhao, and S. Liu, "Co-pyrolysis of biomass and coal in a free fall reactor," Fuel, vol. 86, no. 3, pp. 353-359, 2007.

23. L.-G. Wei, L. Zhang, and S.-P. Xu, "Effects of feedstock on copyrolysis of biomass and coal in a free-fall reactor," Journal of Fuel Chemistry and Technology, vol. 39, no. 10, pp. 728-734, 2011.

24. L. G. Wei, L. Zhang, and S. P. Xu, "Synergetic effects on tar components from copyrolysis of biomass and coal in a free fall reactor," Journal of Fuel Chemistry and Technology, vol. 40, pp. 519-525, 2012.

25. S. Yuan, Z.-H. Dai, Z.-J. Zhou, X.-L. Chen, G.-S. Yu, and F.- C. Wang, "Rapid copyrolysis of rice straw and a bituminous coal in a high-frequency furnace and gasification of the residual char," Bioresource Technology, vol. 109, pp. 188-197, 2012. 
26. S. Li, X. Chen, L. Wang, A. Liu, and G. Yu, "Co-pyrolysis behaviors of saw dust and Shenfu coal in drop tube furnace and fixed bed reactor," Bioresource Technology, vol. 148, pp. 24-29, 2013.

27. Kobayashi, H., Howard, J.B., and Sarofim, A.F. Coal devolatilization at high temperatures. Symp. Int. Combust. 1977; 16, 411-425.

28. Gavalas, G.R. Coal Pyrolysis (1982). (New York, NY: Elsevier).

29. Blondeau, J., and Jeanmart, H. Biomass pyrolysis in pulverized-fuel boilers: Derivation of apparent kinetic parameters for inclusion in CFD codes. Proc. Combust. Inst. 2011;33:1787-1794.

30. Lehto, J. Determination of kinetic parameters for Finnish milled peat using drop tube reactor and optical measurement techniques. Fuel 2007; 86: 1656-1663.

31. Solomon, P.R., Hamblen, D.G., Carangelo, R.M., Serio, M.A., and Deshpande, G.V. (1988).

32. Sommariva, S., Maffei, T., Migliavacca, G., Faravelli, T., and Ranzi, E. (2010). A predictive multi-step kinetic model of coal devolatilization. Fuel 89, 318-328.

33. M.A. Serio, D.G. Hamblen, et al., Kinetics of Volatile Product Evolution in Coal Pyrolysis : Experiment and Theory, Energy and Fuel, 1987.

34. Wiktorsson, L.-P., and Wanzl, W. (2000). Kinetic parameters for coal pyrolysis at low and high heating rates - a comparison of data from different laboratory equipment. Fuel 79, $701-716$.

35. Arenillas, A., Rubiera, F., Pevida, C., and Pis, J.J. A comparison of different methods for predicting coal devolatilisation kinetics. J. Anal. Appl. Pyrolysis 2001; 58-59: 685701.

36. Vuthaluru, H.B. Thermal behaviour of coal/biomass blends during co-pyrolysis. Fuel Process. Technol. 2004; 85: 141-155.

37. Reschmeier, R., Roveda, D., Müller, D., and Karl, J. Pyrolysis kinetics of wood pellets in fluidized beds. J. Anal. Appl. Pyrolysis 2014; 108: 117-129.

38. Nunn, T.R., Howard, J.B., Longwell, J.P., and Peters, W.A. (1985). Product Compositions and Kinetics in the Rapid Pyrolysis of Sweet Gum Hardwood. Ind Eng Chem Process Dev U. S. 24:3.

39. Reschmeier, R., and Karl, J. Experimental study of wood char gasification kinetics in fluidized beds. Biomass Bioenergy 2016; 85: 288-299.

40. Orfão, J.J.M., Antunes, F.J.A., and Figueiredo, J.L. Pyrolysis kinetics of lignocellulosic materials-three independent reactions model. Fuel 1999; 78: 349-358.

41. Valente, M., Brillard, A., Schönnenbeck, C., and Brilhac, J.-F. (2015). Investigation of grape marc combustion using thermogravimetric analysis. Kinetic modeling using an extended independent parallel reaction (EIPR). Fuel Processing Technology, 2015;131: 297-303.

42. Popova, E., Chernov, A., Maryandyshev, P., Brillard, A., Kehrli, D., Trouvé, G., Lyubov, V., and Brilhac, J.-F. Thermal degradations of wood biofuels, coals and hydrolysis lignin from the Russian Federation: Experiments and modeling. Bioresour. Technol. 2016; 218: 1046- 1054.

43. Papadikis, K., Gu, S., Bridgwater, A.V., and Gerhauser, H. (2009). Application of CFD to model fast pyrolysis of biomass. Fuel Process. Technol. 90, 504-512.

44. Bridgwater AV. Principles and practice of biomass fast pyrolysis processes for liquids. Journal of Analytical and Applied Pyrolysis 1999; 51:3-22.

45. Ranz WE, Marshall WR. Evaporation from drops, Part I. Chemical Engineering Progress 1952; 48: 141-6.

46. Ranz WE, Marshall WR. Evaporation from drops, Part II. Chemical Engineering Progress 1952; 48:173-80. 
47. Lee, I.-B., et al., The past, present and future of CFD for agro-environmental applications. Computers and electronics in agriculture 2013; 93: 168-183.

48. Ismail, T.M., et al., Eulerian - Eulerian CFD model on fluidized bed gasifier using coffee husks as fuel. Applied Thermal Engineering 2016; 106: 1391-1402.

49. Monteiro, E., et al., Experimental and modeling studies of Portuguese peach stone gasification on an autothermal bubbling fluidized bed pilot plant. Energy 2018; 142: 862-877.

50. Peters, B., Classification of combustion regimes in a packed bed of particles based on the relevant time and length scales. Combustion and Flame 1999; 116(1-2): 297-301.

51. Thiele, E.W., Relation between catalytic activity and size of particle. Industrial \& Engineering Chemistry 1939; 31(7): 916-920.

52. Di Blasi, C., Modeling wood gasification in a countercurrent fixed- bed reactor. AIChE Journal, 2004. 50(9): p. 2306-2319.

53. Zhang, L., Xu, S., Zhao, W. and Liu, S. Co-pyrolysis of biomass and coal in a free fall reactor. Fuel 2007; 86(3): 353-359.

54. Huang Y, Wang N, Liu Q, Wang W, Ma X. Co-pyrolysis of bituminous coal and biomass in a pressured fluidized bed. Chinese Journal of Chemical Engineering. $2019 \mathrm{Jul}$ 1;27(7):1666-73.

55. C.Z. Li, Importance of volatile-char interactions during the pyrolysis and gasification of low-rank fuels - a review, Fuel 112 (2013) 609-623.

56. J. Kong, R. Zhao, Y. Bai, G. Li, C. Zhang, F. Li, Study on the formation of phenols during coal flash pyrolysis using pyrolysis-GC/MS, Fuel Process. Technol. 127 (2014) 41-46.

57. P. Liu, D. Zhang, L. Wang, Y. Zhou, T. Pan, X. Lu, The structure and pyrolysis product distribution of lignite from different sedimentary environment, Appl. Energy 163 (2016) 254-262.

58. F. Yang, Y. Hou, W. Wu, M. Niu, S. Ren, Q. Wang, A new insight into the structure of Huolinhe lignite based on the yields of benzene carboxylic acids, Fuel 189 (2017) 408418.

59. Papadikis, K., Gu, S., Bridgwater, A.V., and Gerhauser, H. (2009). Application of CFD to model fast pyrolysis of biomass. Fuel Process. Technol. 90, 504-512.

60. Bridgwater A.V., "Review of fast pyrolysis of biomass and product upgrading", Biomass and 282 bioenergy, Volume 38, March 2012, Pages 68-94. doi:10.1016/j.biombioe.2011.01.048.

61. Greenhalf C.E. , Nowakowski D.J., Harms A.B., Titiloye J.O., Bridgwater A.V., "A 276 comparative study of straw, perennial grasses and hardwoods in terms of fast pyrolysis 277 products" Fuel 108, 2013, 216-230.

62. Al Arni S, Comparison of slow and fast pyrolysis for converting biomass into fuel, Renewable Energy (2017), doi: 10.1016/j.renene.2017.04.060.

63. Quan C and Gao N. Co-pyrolysis of Biomass and Coal: A Review of Effects of Co pyrolysis Parameters, Product Properties, and Synergistic Mechanisms. Department of Environmental Science and Engineering, School of Energy and Power Engineering, Xi'an Jiaotong University, Xi'an,Shaanxi 710049, China.

64. Gates B. C., Huber G. W., Marshall C. L., Ross P. N., Siirola J. and Wang L. Catalysts for emerging energy applications. MRS Bulletin 2008; 33: 429-435.

65. Meng H., Wang S., Chen L., Wu Z., and Zhao J. Thermal behavior and the evolution of char structure during co-pyrolysis of platanus wood blends with different rank coals from northern China. Fuel 2015;158: 602-611. 
66. Aboyade A. O. Model fitting kinetic analysis and characterization of the devolatilization of coal blends with corn and sugarcane residues. Thermochemical Acta 2012 ;530: 95-106.

746

747

748

749

750 